\title{
A Research on 3d Printing Concrete
}

\author{
Manju R, Deepika R, Gokulakrishnan T, Srinithi K, Mohamed M I
}

\begin{abstract}
D printing concrete is an emerging technology in which structures are made only using concrete in layers with the help of Software. With this technology, even geometrically intricate structures, heavy load bearing structures and hydraulic structures can be made easily in no time with less wastage of materials and minimum costs. It does not require any additional form-work during construction andalso the human resource required is comparatively less. It is a sustainable technology which can also be used for aesthetic purpose. This technology was invented by Charles Hull in 1984. This review paper is about the methods of using $3 D$ printer in the construction field and its future trends.
\end{abstract}

Keywords: $3 D$ printing concrete, formwork, sustainable technology

\section{INTRODUCTION}

$3 \mathrm{D}$ printing is a technology for producing $3 \mathrm{D}$ models of an object of any shape or size in layers using computer software. This technology was first invented by Charles Hull in the year 1984, as he designed the first 3D printer. He was the pioneer of the solid imaging process called Stereo lithography and the stereo lithographic file format, which is the widely used format for 3D printing even today. The first solid object from a digital design was printed by Hideo Kodama of Nayoga Municipal Industrial Research Institute. Following this several advancements were made to make the printers more efficient, affordable and applicable for several fields like research, engineering, military, construction and architecture, fashion, medical industry, computer industry, etc. The production of metal parts like engine brackets and nuts began from 2010 .

$3 \mathrm{D}$ printing is mainly based on Additive Manufacturing (AM) process. $\mathrm{AM}$ is defined as the process of joining materials to make objects from 3D model data, usually layer upon layer. In this process the model is first created using CAD software and then transferred to the printer as a set of stereo lithography language, which is then converted to layers that can be laid directly. Each layer has an activating agent and a power material which helps in bonding of the layers. For large scale construction computer-controlled placement of extruded cement-based mortar to create objects in layers.

Revised Manuscript Received on August 19, 2019.

Dr. Manju R, Associate professor, Department of Civil Engineering, Kumaraguru College of Technology, Coimbatore, T.N, India

Deepika R, UG Student, Department of Civil Engineering, Kumaraguru College of Technology, Coimbatore, T.N, India (E-mail: deepika.16ce@kct.ac.in)

Gokulakrishnan T, UG Student, Department of Civil Engineering, Kumaraguru College of Technology, Coimbatore, T.N, India

Srinithi K, UG Student, Department of Civil Engineering, Kumaraguru College of Technology, Coimbatore, T.N, India

Mohamed M I, UG Student, Department of Civil Engineering, Kumaraguru College of Technology, Coimbatore, T.N, India

\section{WORKING}

3D printers of concrete are controlled by g-codes which is a machine language that controls the printer until the desired model is achieved. 3D concrete printers work in the same way as an FDM printer with a main difference being the materials printed: concrete in 3D printer and plastic in FDM printers.3D printers operate using $\mathrm{x}, \mathrm{y}$ and $\mathrm{z}$ axis where $\mathrm{x}$ axis defines the length (moving the rails back and forth), $y$ axis defines the distance between the rails and $\mathrm{z}$ axis defines the height. The area where the construction is to be made is first flattened and the printer along with the nozzle and the robotic arm setup is connected across the printers. A hose is used to connect the nozzle to a concrete truck. The nozzles are used to lay the concrete in layers and the robotic arm is used to fix thedoor and window frames.

Khoshnevis's idea of 3D printing of concrete with counter crafting was an evolving point of this technology. First of all, spatial modeling software are used to create spatial and digital models of the structure. Slicing is made in horizontal layers using special softwares like Slic3r, Ultimaker, Simplify3D, etc. These are then sent to printers from which the structure is printed in layers. (How 3D printing is affecting construction industry)

3D printing of concrete can be done in three steps: preparation of data, preparation of concrete mix and printing of structure. In the first step, the digital model of the object is made and is sliced using suitable softwares. A plan for laying the concrete in layers by the printer is made by the software. Then a proper concrete mix is prepared such that the concrete doesn't harden rapidly causing blockage in the nozzles and has a good workability. In the last step the concrete is made to flow through the nozzles according to the path programmed in the printer. (Additive manufacturing of concrete in construction: potentials and challenges of $3 \mathrm{D}$ printing)

\section{REVIEW ON 3D PRINTING CONCRETE}

Vinod G. Gokhare, Dr. D. N. Raut and Dr. D. K. Shinde from Veermata Jijabai Technological Institute in Mumbai had explained about themodeling, printing, finishing and processes of 3D printing in their Review paper on "3DPrinting Aspects and Various Processes Used in the 3DPrinting". 3D printable models can be generated with the help of 3D scanner or via CAD design packages. A software called "slicer" is used to process 3D model before printing it from STL file. The 3D model is converted into a series of thin layers and generates a G-code file from STL file through the slicer. By using the G-code instructions, 3D printer put thelayers of powder, liquid or sheet material to 


\section{A Research on 3d Printing Concrete}

construct a model from a series of cross-sections of a model. These layers, which are similar to the virtual cross sections from the CAD model, are fused to produce the final shape of a model. They also explained about the methods like Selective Laser Melting(SLM), Stereolithography, Selective Laser Sintering (SLS), Laminated Object Manufacturing and Fused Deposition Modeling (FDM).

"A review of 3D concrete printing systems and materials properties: current status and future research prospects" is done by Suvash Chandra Paul and Gideon P.A.G. van Zijl from Nanyang Technological University, Singapore. In this paper, they presented an outline of the current status of 3D printing concrete for construction including material properties required for the quality of $3 \mathrm{D}$ printing concrete structures or structural elements and current printing methods. This paper is also explained about three categories of $3 \mathrm{D}$ printing concrete systems namely,Robotic Crane and Gantry systems. They elaborated the material compositions as well as fresh and hardened properties of mixes currently used for 3D printing concrete. This paper also presents an overview of the state of art of 3D printing concrete systems and materials.

Mehmet Sakin, Yusuf Caner Kiroglu had recommended BIM in their review paper on"3D Printing of Buildings: Construction of the Sustainable Houses of the Future by BIM ". Building Information Modelling is an integrated process designed to create and manage building data from design through construction. It can also be used in building maintenance, life cycle,cost analysis and operations.Integration of BIM method with 3D printing modelling will be effective for better design, cost reduction, energy efficiency and isolation of a structure.

\section{D PRINTING STRUCTURES}

$>$ The 3D Print Canal Housein Amsterdam is a threeyear, publicly accessible 3D printing building done by an international team of members from various sectors works together in the project "Research \& Design by Doing" project.

$>$ The first residential building in Yaroslavl, Russia printed with a $3 \mathrm{D}$ construction printer. It is around the area of 2,985 sq. $\mathrm{m}$.

$>$ Dutch and Chinese demonstration projects are started developing 3D-printed buildings in Dubai, China and Netherland. They first builta small 3D printed concrete house in 2017 to create awareness among the people about the new building technologies.

$>$ The Building on Demand (BOD) is the first 3D printed house in Europe. COBOD International done this project for a small 3D printed office hotel in Copenhagen.

$>$ The first 3D printed pedestrian bridge with the DShape technology is constructed in Alcobendas, having a total length of 12 meters and a width of 1.75 meters. It is printed with micro-reinforced concrete.

$>3 \mathrm{D}$ printed fountain is constructed in Palekh, Russia. It is about 26 meters in diameter and 2.2 meters in depth. It is printed by AMT construction.

\section{ADVANTAGES}

- Using 3D printing technologies for the construction of structures would greatly reduce the cost involved with it as it reduces the number of materials used and also avoids the wastage of the materials. It also reduces the labor cost as the requirement of manpower is less subsequently reducing the cost associated with accidents and injuries.

- The designs which are uploaded in the form of CAD can be printed in no time. Thus, 3D printers can complete the construction of a single storeyed building within 12 to 24 hours leading to speedy construction of structures.

- With the advancements made in technologies it has been proved that the structures constructed using 3D printing have higher strength and durability which can withstand extremes of temperature.

- Even intricate designs can be accurately constructed easily without any increase in cost and permitting the better usage of space.

- This method is more sustainable because most of the materials used in these processes are recyclable and reusable. Also, the carbon footprint produced by this method is much lesser than the conventional methods.

- This method helps in the easy verification of designs by creating prototypes which would eliminate the occurrence of errors in the mass productions.

- The use of formworks, scaffolds etc., can be avoided which would reduce about $40 \%$ of the construction cost.

\section{DISADVANTAGES}

- Though the cost of construction maybe reduced by 3D printing, the cost of the printers is huge which is a draw back.

- Skilled laborers who can work efficiently with the 3D printers and CAD are required.

- 3D printers consume high amount of energy. According to a research it has been shown that it consumes about 100 times more electrical energy than the conventional methods.

- Since the size of the printers is huge it creates problems in the onsite storage.

\section{APPLICATION}

- This technology can be used to build disaster shelters easily using locally available materials within 2-3 hours having a lifespan of about 6 years.

- The improvements made in 3D printing allow the printing any kind of material. Even complex and expensive works, like the artifacts made using wood, ceramic, tiles, etc., can be made easily with higher quality thereby increasing the life of the structures.

- 3D printing can also be used to print home decors, furnishing products and other structures for architectural detailing. 
- The size of the aggregates used in 3D printing are generally less than $6 \mathrm{~mm}$. Concrete being weak in tension and the usage of smaller sized aggregates may lead to structural collapse. To overcome this, steel fibers may be introduced along with the concrete materials during printing which would give the necessary strength.

- The European Space Agency (ESA) collaborated with a group of architects to build up habitats on the moon by $3 \mathrm{D}$ printing using locally available materials, i.e. lunar soil.

\section{FUTURE SCOPE \& RESULTS}

Apart from the construction of buildings, 3D printing can also be used for several other purposes in the construction field. Binder jet is a method of 3D printing in which powder and binding materials are used. However, the accuracy and the appearance of the structure may not be well defined. This problem can be solved by reducing the size of the nozzles and using finer materials. This can also be done by using limestone and other construction materials and build houses in remote areas and to build disaster relief structures. 3D printing technology can be used to create hybrid version of injection molding to create larger prototypes with much lesser cost. It can also be used to print walls reinforced with steel structures and make reusable concrete formworks. This technique would help in increasing the aesthetic appearance of the 3D printed structures. Bricks and concrete blocks can also be printed and laid using 3D printers using locally available materials. The recycled concrete can be used to make light weight concrete blocks using $3 \mathrm{D}$ printers. This would greatly reduce the amount of carbon dioxide emitted and reduce the generation of construction waste.

\section{REFERENCES}

1. Izabela Hager, Anna Golonka, Roman Putanowicz; “3D Printing of Buildings and Building Components as the Future of Sustainable Construction"; International Conference on Ecology and New Building Materials and Products, ICEBMP 2016

2. Mostafa Yossef, A Chen; "Applicability and Limitations of 3D Printing for Civil Structures"; Civil, Construction and Environmental Engineering Conference Presentations and Proceedings.

3. R.A. Buswell, J. Dirrenberger; "3D Printing Using Concrete Extrusion: A Roadmap for Research", Cement and Concrete Research.

4. Ibrahim Engin Ozturk, Gozde Basak Ozturk; "The Future of 3D Printing Technology in the Construction Industry: A Systematic Literature Review", Eurasian Journal of Civil Engineering and Architecture, Volume 2 Issue 2.

5. Nagaraj, B., and P. Vijayakumar. "Controller tuning for industrial process-a soft computing approach." Int. J. Advance. Soft Comput. Appl 4, no. 2 (2012).

6. Yi Wei Daniel Tay, Biranchi Panda, Suvash Chandra Paul, Nisar Ahamed Noor Mohamed, Ming Jen Tan and Kah Fai Leong, "3d Printing Trends in Building and Construction Industry: A Review"

7. Bos F, "Additive Manufacturing of Concrete in Construction: Potentials and Challenges of 3D Printing"

8. Nithesh Nadarajah, "Development of Concrete 3D Printing"

9. https://m.all3dp.com/2/concrete-3d-printing-how-to-doand-application/ 